Artigo / Article

\title{
Proliferação monoclonal B CD5+ subclínica
}

\section{Monoclonal B CD5+ subclinical proliferation}

Roberto P. Falcão

\section{Introdução}

A leucemia linfocítica crônica (LLC) é caracterizada por linfocitose B monoclonal persistente (CD5+, CD23+, com expressão fraca ou ausente de imunoglobulinas de superfície) de $>5 \times 10^{9} / \mathrm{L}$ persistindo por mais de um mês (NCI Working Group) ou $>10 \times 10^{9} / \mathrm{L}$ (IWCLL), com linfócitos pequenos, núcleo redondo, cromatina densa e citoplasma escasso. A medula óssea está infiltrada por $>30 \%$ de linfócitos. As células da LLC diferem dos linfócitos B normais pela forte expressão de CD5 e CD23, associada a baixa expressão de CD79b, CD20 e de cadeias leves de imunoglobulinas de um único subtipo kappa ou lambda. Assim, o estudo por citometria de fluxo com quatro cores usando a combinação CD19/CD5/CD79b/CD20 permite o reconhecimento na janela da população $\mathrm{CD} 19+$ de células $\mathrm{CD} 5^{\text {forte }}$, CD79b fraco, CD20 fraco.

$\mathrm{O}$ emprego de citometria de fluxo com quatro cores, usando CD5, CD19, CD20 e CD79b, para a detecção de doença residual mínima em pacientes com LLC tratados com quimioterapia intensiva, é eficiente na detecção de um nú- mero reduzido de células B-LLC e apresenta sensibilidade de $1 \mathrm{em} 10^{5}$. A aplicação desta mesma técnica no sangue periférico de pessoas normais demonstrou a presença, em $0,14 \%$ a $5,5 \%$ dos indivíduos estudados, de células com um perfil imunológico semelhante a LLC, sendo que este valor aumentava com o aumento da idade da população estudada. Estas células eram monotípicas com relação à expressão de cadeias leves de imunoglobulina de membrana. Um outro grupo onde foi detectado a presença de linfocitose B monoclonal era constituído de familiares de pacientes pertencentes a famílias com dois ou mais membros portadores de LLC, a chamada LLC familiar. Contudo, devemos enfatizar que, apesar de ser uma linfocitose $\mathrm{B}$ monoclonal, não existem evidências de que as células sejam malignas. Como a maioria das amostras testadas era anônima, não foi possível estudá-las de uma maneira seqüencial para definir o seu comportamento. Estes casos representam o pólo oposto extremo em relação à LLC.

Existe um terceiro grupo de pacientes que não possuem os requisitos para o diagnóstico de LLC estabelecidos pelo NCI Working Group on CLL, isto é, com contagens de

Professor titular de Clínica Médica - Hematologia da Faculdade de Medicina de Ribeirão Preto-USP

Departamento de Clínica Médica - Faculdade de Medicina de Ribeirão Preto

Correspondência para: Roberto Passeto Falcão

Hospital das Clínicas da Faculdade de Medicina de Ribeirão Preto - Campus USP

14048-900 - Ribeirão Preto-SP

Tel.: (16) 2101-9364

E-mail:rpfalcao@fmrp.usp.br 
linfócitos no sangue periférico $<5 \times 10^{9} / \mathrm{L}$ e $<30 \%$ de linfócitos na medula óssea e sem adenopatia. Este grupo denominado de LLC precoce ou inicial será discutido em parágrafos seguintes.

Finalmente, existe um quarto grupo de pacientes com diagnóstico bem definido de LLC com linfocitose B monoclonal e doença estável, não progressiva, e com sobrevida semelhante a de uma população controle pareada por sexo e idade. Diversos termos têm sido usados para descrever esta forma de LLC: linfocitose B monoclonal benigna, linfocitose crônica idiopática persistente, linfocitose B monoclonal de significado indeterminado e LLC smoldering.

\section{Linfocitose de células-B monoclonal}

$\mathrm{O}$ termo linfocitose $\mathrm{B}$ monoclonal refere-se à detecção por citometria de fluxo da presença no sangue circulante de indivíduos aparentemente normais de um número reduzido de células monoclonais $\mathrm{B}$, indistinguíveis das encontradas na LLC. Com o uso de citometria de fluxo com três ou quatro cores é possível detectar níveis reduzidos $\left(<0,005 \times 10^{9}\right.$ células/L) de clones circulantes de linfócitos B com características de membrana similares às da LLC. Devido à existência na literatura de uma variedade de termos para designar estes casos, um grupo de trabalho foi organizado para uniformizar esta nomenclatura e os resultados foram recentemente publicados. ${ }^{1}$

Critérios diagnósticos de linfocitose B monoclonal

A proposta deste grupo para a caracterização de linfocitose $\mathrm{B}$ monoclonal (LBM) no sangue periférico inclui as seguintes recomendações.

1. Detecção de uma subpopulação de linfócitos B monoclonais no sangue periférico com

- relação kappa:lambda $>3: 1$ ou $<0,3: 1$, ou

- mais de $25 \%$ de linfócitos B com expressão fraca ou ausente de cadeias leves de imunoglobulina na membrana, ou

- imunofenótipo específico da doença.

2. Demonstração laboratorial de que a população monoclonal B é estável durante um período de, pelo menos, três meses.

3. Critérios de exclusão

- linfoadenomegalia e/ou organomegalia, ou

- associação com doença auto-imune ou infecciosa, ou

- contagens de linfócitos B >5 x 10\%/L, ou

- qualquer outro achado diagnóstico de doença linfoproliferativa B. Entretanto, paraproteinemia pode estar presente ou associada a LBM e deve ser avaliada independentemente.

4. Subclassificação

- $\mathrm{CD}^{+} \mathrm{CD}_{23} 3^{+}$: esta é a subcategoria predominante e corresponde ao imunofenótipo da LLC.

- $\mathrm{CD}^{+} \mathrm{CD} 23:$ : correlaciona com níveis moderados de expressão de CD20 e CD79b da LLC atípica.
- CD5: corresponde a doença linfoproliferativa nãoLLC.

\section{Observações:}

1. Mais de um conjunto de reagentes de cadeias leves kappa/lambda pode ser usado; a detecção de qualquer população B monoclonal por restrição de cadeia leve é suficiente. Confirmação por PCR de cadeia pesada de Ig pode ser útil, mas não é essencial.

2. A população LBM pode representar a minoria das células B totais quando identificada pelo imunofenótipo específico da doença. Ela pode ser demonstrada mesmo se a relação kappa:lambda total for normal. Nesta eventualidade a clonalidade deve ser demonstrada na população identificada pelo imunofenótipo específico.

3. LBM sem imunoglobulina de superfície está associada a $\mathrm{LBM} \mathrm{CD} 5^{+} \mathrm{CD} 23^{+}$.

4. A confirmação da clonalidade deve ser atestada pelo uso de um mínimo de três cores (CD19 ou CD20, anti-kappa e anti-lambda), embora seja preferível o uso de quatro ou mais cores.

5. Aumentos da intensidade de fluorescência da imunoglobulina de superfície, de CD20 ou de CD79b devem ser assinalados.

6. O número total de células analisadas deve permitir a formação de um agrupamento (cluster) contendo, pelo menos, 50 eventos.

7. A repetição de análises por citometria de fluxo pode ser desnecessária se a clonalidade for confirmada por outros métodos como, por exemplo, a hibridização in situ ou PCR.

\section{História natural}

A prevalência da LBM é maior que a da LLC. Assim, se ela for considerada a precursora da LLC, um grande número de casos deve regredir ou permanecer inalterado para explicar esta diferença de prevalência. Um comportamento semelhante foi descrito em pacientes em fases iniciais de LLC que apresentam doença estável por vários anos ou, ocasionalmente, apresentando diminuição da contagens de células leucêmicas. Neste sentido, a observação de pacientes com clones, $\mathrm{CD} 5^{+} 23^{+}$que não preenchem os critérios diagnósticos de LLC mostrou que, em cinco anos, $60 \%$ apresentavam linfocitose estável ou regressiva, $35 \%$ mostraram aumento da linfocitose e apenas $5 \%$ passaram a necessitar tratamento. ${ }^{2}$ Portanto, até o momento, a hipótese de que a LBM seja precursora da LLC e de linfomas não-Hodgkin é ainda presumível e estudos longitudinais serão necessários para definir esta relação. Portanto, a situação no momento da relação entre a LBM e a LLC é diferente da existente entre a gamopatia monoclonal de causa indeterminada e o mieloma múltiplo onde já está demonstrado que o risco relativo de progressão é 25 vezes maior, em um período de trinta anos, com taxa de progressão de $1 \%$ ao ano. 
Existem alguns estudos determinando a freqüência de clones de LLC em pessoas saudáveis. Os resultados variam com o método de detecção empregado e com a idade média do grupo estudado, e oscilam entre $0,14 \%$ e $5,5 \%$. Assim, Vogt et al, ${ }^{3}$ estudando uma população de 1.499 indivíduos com mais de 45 anos, encontraram 11 pessoas $(0,7 \%)$ com linfocitose caracterizada pela presença de linfócitos B $\mathrm{CD} 5+\mathrm{CD} 20^{+ \text {fraco }}$. Marti et $\mathrm{al}^{4}$ demonstraram monoclonalidade $\kappa / \lambda$ em três desses 11 indivíduos. Jack et $\mathrm{al}^{5}$ (1997), usando citometria de fluxo com três cores encontrou valores entre $1,5 \%$ a $2 \%$ em pessoas com mais de 40 anos. Usando marcação com quatro cores, Slade, ${ }^{6}$ em 1999, encontrou $0,6 \%$ de indivíduos com clones anormais (13 de 1.985 indivíduos), enquanto Rawstron et $\mathrm{al}^{7}$ detectaram 3,5\% em um total de 910 pacientes ambulatoriais pesquisados. Rachel et $\mathrm{al}^{8}$ encontraram $0,14 \%$ em 5.138 doadores adultos usando três cores. Ghia et $\mathrm{al}^{9}$ estudaram 500 indivíduos saudáveis, com idade superior a 65 anos, usando quatro cores e restrição de cadeias leves e encontrou freqüência de $3,8 \%$ de casos com relação $\kappa / \lambda$ maior que $3: 1$ ou menor que $1: 3$; usando uma outra janela baseada na expressão de CD20/CD5/ CD79b, a freqüência encontrada foi de 5,5\%. Estes clones $\mathrm{B}$ CD5+23+ foram isolados em colunas imunomagnéticas e analisados. ${ }^{10}$ Usando um conjunto de 18 antígenos (CD) foi demonstrado que a LBM apresenta perfil imunofenotípico semelhante ao da LLC e diferente dos linfócitos B normais. $\mathrm{O}$ estudo citogenético por FISH mostrou a presença de deleção 13q14 em 16/35 casos estudados e trissomia $12 \mathrm{em}$ 3/21 casos; deleções do 17p e 11q23 não foram detectadas. Intraclonalidade homogênea foi demonstrada em 5/12 casos, enquanto a intraclonalidade heterogênea foi observada em 4/12 casos. A homogeneidade clonal é característica das proliferações neoplásicas, enquanto as proliferações reacionais mostram heterogeneidade clonal. Estes estudos mostram uma associação próxima entre a LLC e a MBL tanto do ponto de vista fenotípico como genotípico. ${ }^{10} \mathrm{~A}$ evolução destes casos é desconhecida pois as amostras estudadas não haviam sido identificadas.

\section{Linfocitose B monoclonal em indivíduos sadios pertencentes a famílias com pelo menos dois membros com LLC (LLC familiar)}

A leucemia linfóide crônica familiar ou familial é definida como a ocorrência da doença em dois ou mais membros de uma mesma família. Existe na literatura o registro de mais de cinqüenta famílias que preenchem este requisito. Os estudos de parentes sadios de primeiro grau de pacientes pertencentes a estas famílias mostraram que a freqüência de LBM era maior do que a detectada na população em geral. Um estudo ${ }^{11,12}$ que analisou 59 indivíduos sadios, advindos de 21 famílias, encontrou oito indivíduos $(13,5 \%)$ com células semelhantes às encontradas na doença. Em outra publicação ${ }^{13}$ foram estudados 33 indivíduos pertencentes a nove famílias com LLC e encon- tradas células B monoclonais em seis (18\%). O seguimento longitudinal destes portadores de clones anormais poderá esclarecer se a presença dos mesmos é indicativa de maior probabilidade de desenvolvimento da doença. Embora a evolução destes casos ainda não permita responder a esta questão recomenda-se que os potenciais doadores de medula óssea alógena sejam estudados previamente para a detecção de doença residual mínima para evitar problemas futuros nos receptores.

\section{Linfocitose B monoclonal CD5+23+ precoce ou inicial com contagens de linfócitos no sangue periférico $<5 \times 10^{9} / \mathrm{L}$ e com $<30 \%$ de linfócitos na medula óssea}

Existem pacientes que não possuem os requisitos para o diagnóstico de LLC estabelecidos pelo NCI Working Group on CLL (1996), contagens de linfócitos no sangue periférico $<5 \times 10^{9} / \mathrm{L}$ e $<30 \%$ de linfócitos na medula óssea e sem adenopatia. Rawstron et al $^{2}$ estudaram um total de 344 pacientes com linfocitose B monoclonal CD5 $+23+$ de $<5 \times 10^{9} /$ $\mathrm{L}$ e $<30 \%$ de linfócitos na medula óssea e sem adenopatia. Eles chamaram esta entidade de LLC precoce ou inicial (early). O seguimento destes pacientes pelo tempo mediano de cinco anos revelou que aproximadamente $60 \%$ tinham linfocitose estável ou em regressão; 35\% apresentaram aumento da contagem de linfócitos e 5\% tiveram necessidade de tratamento. Ademais, seis de 47 pacientes mostraram cinética de progressão bifásica, com uma fase inicial estável seguida por aumento mais pronunciado da contagem de linfócitos após 3,5 anos (variação 0,5-7 anos) da apresentação, sugerindo a ocorrência de um evento secundário. Infelizmente estes resultados foram relatados apenas sob a forma de resumo.

\section{Leucemia linfocítica crônica estável}

A análise da literatura revela a existência de diversas terminologias usadas para designar pacientes que preenchem os critérios estabelecidos pelo NCI Working Group on CLL, mas cuja doença permanece estável por longos períodos de tempo. Entre os termos existentes temos a linfocitose B monoclonal benigna, a linfocitose crônica idiopática, a linfocitose B monoclonal de significado indeterminado e a LLC indolente (smoldering)

\section{Linfocitose B monoclonal benigna}

Este termo foi usado pela primeira vez por Han et al, ${ }^{14}$ em 1984, para designar o quadro clínico de vinte pacientes com LLC em estágio Rai 0 , selecionados de um total de 500 casos, que apresentavam doença estável, sem progressão, por 6,6 a 24 anos, sem tratamento. O número médio de linfócitos ao diagnóstico era $20 \times 10^{9} / \mathrm{L}$, com variação entre 10 e 43,7 x $10^{9} / \mathrm{L}$, enquanto no final do seguimento o número médio era 20.6 x 10\%/L com variação entre 1 e 47 x 10\%/L. Mandelli 
et $a{ }^{15}$ descreveram o mesmo tipo de evolução em 327 pacientes com estágio Rai 0 em um total de 1.777 casos de LLC.

\section{Linfocitose crônica idiopática, persistente}

Bassan et al ${ }^{16}$ empregaram este termo para descrever seis casos de LLC com contagens de linfócitos estável e $<15$ x $10 \% / \mathrm{L}$ e $<25 \%$ de linfócitos na medula óssea e sem hepatoesplenomegalia ou adenomegalia.

\section{Linfocitose monoclonal B de significado indeterminado}

$\mathrm{O}$ termo linfocitose monoclonal B de significado indeterminado foi usado por Kimby et $a l^{17}$ para se referir a uma forma de LLC (linfocitose e infiltração de medula óssea) mas sem sintomas ou sinais da doença. Os seguintes critérios foram usados para a definição desta forma de LLC:

1. Linfocitose monoclonal B determinada por restrição de cadeias leves de membrana,

2. Ausência de sintomas constitucionais (febre, perda de peso, sudorese noturna, etc),

3. Ausência de aumento de linfonodos,

4. Ausência de hepato-esplenomegalia,

5. Ausência de anemia ou plaquetopenia,

6. Contagem de leucócitos estável.

Além disso, os pacientes deveriam permanecer em condição clínica estável (doença não progressiva) durante um total de pelo menos sessenta meses e/ou por pelo menos dois anos após o estudo imunofenotípico. Entretanto, não existe consenso sobre a duração do período de seguimento necessário para a definição desta forma de LLC.

\section{Leucemia linfóide crônica indolente (smoldering)}

Montserrat et a $\mathrm{l}^{18}$ definiram como LLC smoldering um subgrupo de pacientes com estágio Binet A, correspondendo a $30 \%$ dos pacientes com LLC, cuja expectativa de vida não diferia da população controle pareada por sexo e idade. Os achados clínico-hematológicos destes pacientes eram hemoglobina $>13 \mathrm{~g} / \mathrm{dL}$, número absoluto de linfócitos circulantes $<30 \times 10^{9} / \mathrm{L}$, padrão não difuso de envolvimento da medula óssea e tempo de duplicação de linfócitos (TDL) $>12$ meses. Posteriormente, o Grupo Cooperativo Francês de LLC $^{19}$ analisou um grande série prospectiva de LLC estádio A e propôs uma outra definição de LLC smoldering que difere da de Montserrat pela exclusão do TDL e da histologia da medula óssea; o método usado para avaliar o comprometimento medular baseava-se na percentagem de linfócitos em esfregaços de medula óssea obtidos por punção aspirativa. Pacientes com estágio A' caracterizado por contagens de linfócitos $<30 \times 10^{9} / \mathrm{L}$ e $\mathrm{Hb}>12 \mathrm{~g} / \mathrm{dL}$ e com $<80 \%$ de linfócitos nos aspirados de medula óssea apresentam sobrevida igual à de uma população controle normal pareada por sexo e idade.

Portanto, o termo proliferação monoclonal B-CD5+ subclínica, que é o título desta revisão, refere-se a um conjunto de entidades descritas em indivíduos normais, em familiares de pacientes com LLC familiar, e em pacientes com linfocitose $\mathrm{B}$ monoclonal que não preenchem os critérios estabelecidos, em 1996, pelo NCI Working Group on CLL. Estas três entidades são reconhecidas atualmente como linfocitose de células B monoclonais. Existem ainda casos que preenchem os critérios diagnósticos de LLC, mas que apresentam doença estável, sem progressão e que também foram denominados de leucemia linfocítica crônica benigna. Este quadro poderá mudar nos próximos meses. No XI International Workshop on CLL, realizado em New York, em setembro de 2005, foi apresentada uma proposta de atualização dos critérios do NCI-WG 1996 para LLC. Uma das sugestões é que a LLC poderia ser diagnosticada, independentemente das contagens de linfócitos, na presença de aumento permanente da contagem de linfócitos, de natureza clonal. Não existe ainda definição do valor deste limite de corte.

\section{Abstract}

Monoclonal B CD5+ subclinical proliferation is related to a group of clinical or laboratory entities described in normal subjects (0.14\%-5.5\%), in normal members of families with cases of familial CLL (13.5\%-18\%) and in patients with monoclonal B lymphocytosis with lymphocyte counts of $<5 \times 10^{\circ} / \mathrm{L}$ and with $<30 \%$ of lymphocytes in bone marrow. These three entities are now named monoclonal B-cell lymphocytosis. Additionally, there are cases that fulfill the diagnostic criteria for CLL but present with stable non-progressive disease and are also named as benign monoclonal $B$ lymphocytosis, smoldering CLL, idiopathic persistent chronic lymphocytosis, and B-monoclonal lymphocytosis of undetermined significance. Rev. bras. hematol. hemoter. 2005;27(4):267-271.

Key words: Chronic lymphocytic leukemia; monoclonal B lymphocytosis.

\section{Referências Bibliográficas}

1. Marti GE, Rawstron AC, Ghia P et al. Diagnostic criteria for monoclonal B-cell lymphocytosis. British Journal of Haematology 2005; 130:325-332.

2. Rawnstron AC, de Tute R, O'Connor SJM et al. The natural history of "early CLL" Blood 2003;102:188a.

3. Vogt RF, Meredith MNK, Powell J et al. Results in eleven individual with B-CLL like phenotypes detected in environmental health studies. In: Proceedings of a USPHS Workshop on Laboratory Approaches to determining the Role of Environmental Exposures as Risk Factors for BCell Chronic Lymphocytic Leukemia and Other B-Cell Lymphoproliferative Disorders (ed by GE Marti, RF Vogt and VE Zenger), pp1935. USPHS, Atlanta, GA.

4. Marti GE, Muller J, Stetler-Stevenson M et al. B-cell monoclonal lymphocytosis in three individual living near a hazardous waste site. In: Proceedings of a USPHS Workshop on Laboratory Approaches to determining the Role of Environmental Exposures as Risk Factors for BCell Chronic Lymphocytic Leukemia and Other B-Cell Lymphoproliferative Disorders (ed by GE Marti, RF Vogt and VE Zenger), pp 3750. USPHS, Atlanta, GA. 
5. Jack A, Richards S, Evans P et al. Population screening for B-cell monoclonal lymphocytosis using PCR and flow cytometry to determine immunophenotypes. In: Proceedings of a USPHS Workshop on Laboratory Approaches to determining the Role of Environmental Exposures as Risk Factors for B-Cell Chronic Lymphocytic Leukemia and Other B-Cell Lymphoproliferative Disorders (ed by GE Marti, RF Vogt and VE Zenger), pp 93-96. USPHS, Atlanta, GA

6. Slade BA. Follow-up investigation of B-cell abnormalities identified in previous ATSDR health studies: US Department of Health and Human Services. Public Health Service, Publication \# PB99-138331.

7. Rawstron AC, Green MJ, Kuzmicki A et al. Monoclonal B lymphocytes with the characteristics of "indolent" chronic lymphocytic leukemia are present in $3.5 \%$ of adults with normal blood counts. Blood 2002; 100; 635-639.

8. Rachel JM, Zucker ML, Plapp FV et al. B cell monoclonal lymphocytosis in blood donors. Blood 2002;100:590a.

9. Ghia P, Prato G, Scielzo C et al. Monoclonal CD5+ and CD5- B lymphocyte expansions are frequent in the peripheral blood of the elderly. Blood 2004;103:2.337-2.342.

10. Bennett FL, O'Connor SJM, Fenton JAL et al. The biological relationship between $\mathrm{CD} 5+23+$ monoclonal B-cell lymphocytosis and chronic lymphocytic leukemia. Leukemia Lymphoma 2005;46, suppl 1:S67

11. Rawstron AC, Yuille MR, Fuller J et al. Inherited predisposition of CLL is detectable as subclinical monoclonal B-lymphocyte expansion. Blood 2002;100:2.289-2.291.

12. Rawstron A, Hillmen P, Houston R. Clonal lymphocytes in persons without known chronic lymphocytic leukemia (CLL): implications of recent findings in family members of CLL patients. Seminars in Hematology 2004;41:192-200

13. Marti GE, Carter P, Abbasi F et al. B-cell monoclonal lymphocytosis and B-cell abnormalities in the setting of familial B-cell chronic lymphocytic leukemia. Cytometry 2003;52B (Clinical Cytometry):1-12
14. Han T, Ozer H, Gavigan M et al. Benign monoclonal B cell lymphocytosisA benign variant o CLL: clinical, immunologic, phenotypic and cytogenetic studies in 20 patients. Blood 1984;64:244-252.

15. Mandelli F, De Rossi G, Mancini P et al. Progression of chronic lymphocytic leukemia : a retrospective multicentric study from the GIMEMA group. Journal of Clinical Oncology 1987;5:398-404.

16. Bassan R, Buzzetti M, Marini B et al. Investigation of chronic lymphocytosis in adults. American Journal of Clinical Pathology 1988; 89:783-787.

17. Kimby E, Mellstedt H, Bjorkholm M, Holm G. Clonal cell surface structures related to differentiation, activation and homing in B-cell chronic lymphocytic leukemia and monoclonal lymphocytosis of undetermined significance. European Journal of Haematology 1989;43:452-459.

18. Montserrat E., Vinolas N, Reverter JC et al. Natural history of chronic lymphocytic leukemia: on the progression and prognosis of early clinical stages. Nouvelle Revue Française d'Hematologie 1988;30:359-361.

19. French Cooperative Group on Chronic Lymphocytic Leukemia. Natural history of stage A chronic lymphocytic leukemia untreated patients. British Journal of Haematology 1990;76:45-57.

Avaliação: Carlos Sergio Chiattone

(publicado após acordo do Editor)

Conflito de interesse: Artigo derivado do II Encontro Brasileiro de Consenso da LLC

Recebido: 30/10/2005

Aceito: 15/11/2005 